\title{
A Benign Renal Cyst Containing Liesegang Rings Mimicking a Renal Cell Carcinoma: A Case Report
}

\author{
Andrew Wood ${ }^{a} \quad$ Marie O'Donnell $^{a} \quad$ Ana Casado $^{b}$

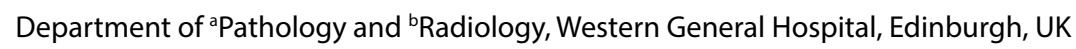

\section{Key Words \\ Liesegang rings $\cdot$ Kidney $\cdot$ Pseudotumor}

\begin{abstract}
Liesegang rings are uncommon pathological findings which may cause diagnostic dilemmas for pathologists. Awareness of their appearance is important to avoid over diagnosis of parasitic infection, algal contamination and psammoma bodies. Liesegang rings are benign, lamellar structures with radial striations and a central amorphous core. They are found in a variety of tissues and fluids in both an intra- and extra-cellular sites. We present here a case of a cystic renal lesion containing Liesegang rings mimicking a renal cell carcinoma.

Copyright $\odot 2013$ S. Karger AG, Basel
\end{abstract}

\section{Case Report}

A 68-year-old gentleman presented with left hip pain of 10 to 15 years duration. He had a significant past medical history of hypertension, left ventricular dysfunction and Crohn's disease. He subsequently underwent a left total hip replacement complicated by postoperative retention and a urinary tract infection.

An abdominal ultrasound scan revealed a suspicious lesion in the lower pole of the left kidney (fig. 1). CT scan confirmed the presence of an exophitic mass lesion, which demonstrated an internal area suggestive of necrotic or cystic changes (fig. 2). The lesion had a lobulated irregular contour with associated stranding of the peri-lesional fat. The appearances although atypical were interpreted as an isolated solid renal tumor; the patient subsequently underwent a left laparoscopic radical nephrectomy.

\section{KARGER}

Fax +4161306 1234

E-Mail karger@karger.ch

www.karger.com
(C) 2013 S. Karger AG, Basel

1015-9770/13/0071-0037\$26.00/0

Accessible online at:

www.karger.com/cur

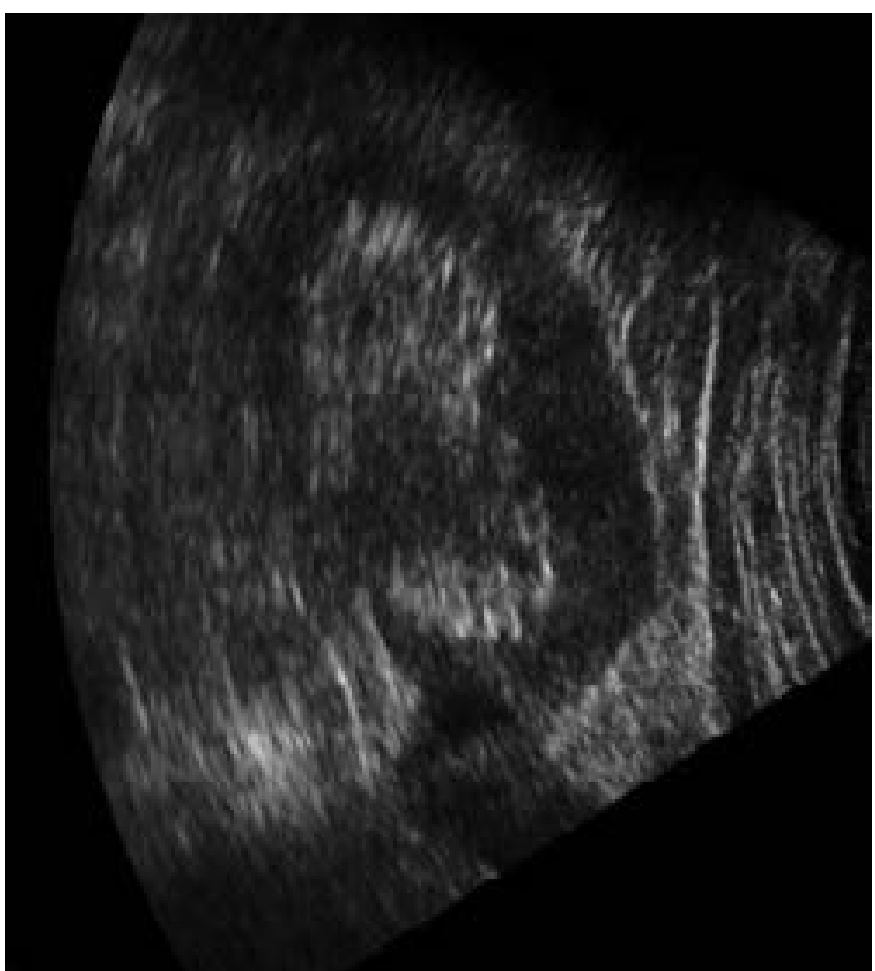

Fig. 1. The ultrasound scan of the left kidney shows a hypoechoic lesion protruding into perinephric fat at the lower pole.

The surgical specimen showed a well circumscribed circular tan brown lesion in the lower pole of the left kidney which measured $28 \mathrm{~mm}$ in maximum dimension. The lesion was surrounded 


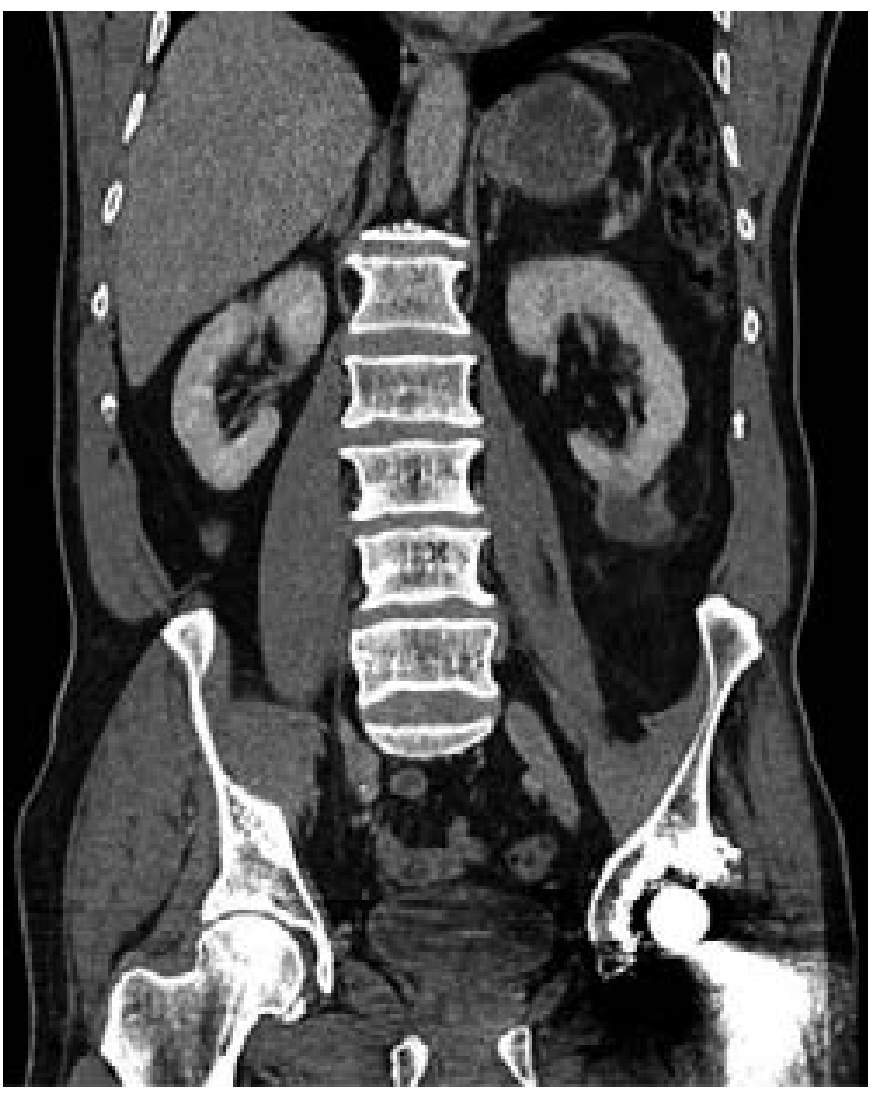

Fig. 2. The CT scan confirmed the presence of an exophytic mass at the lower pole of the left kidney with internal low attenuation suggestive of necrotic or cystic changes.

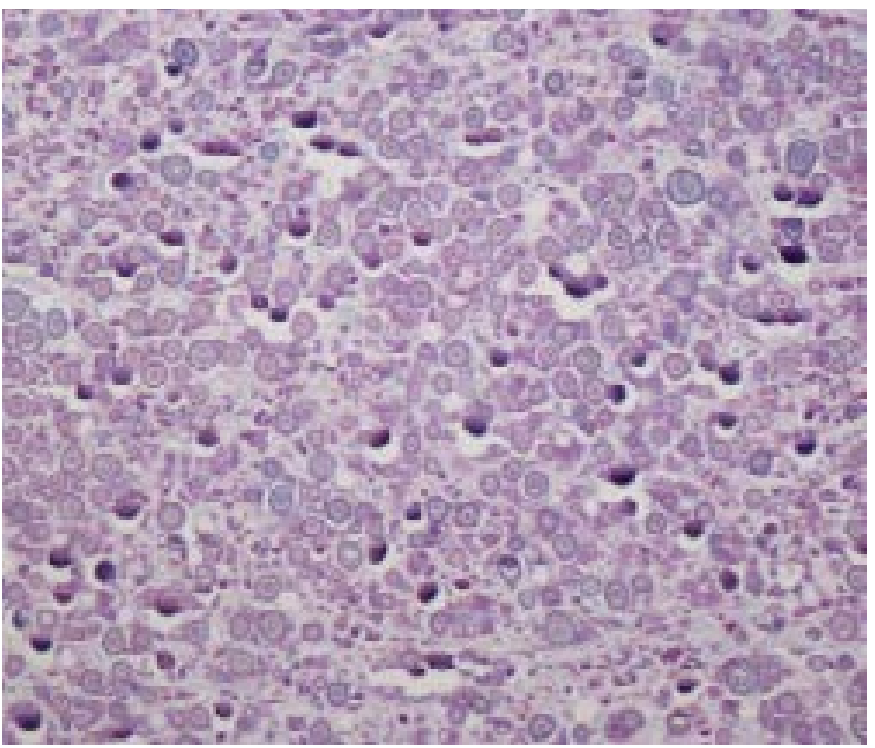

Fig. 4. The appearance of the Liesegang rings is accentuated on PAS staining (x100).

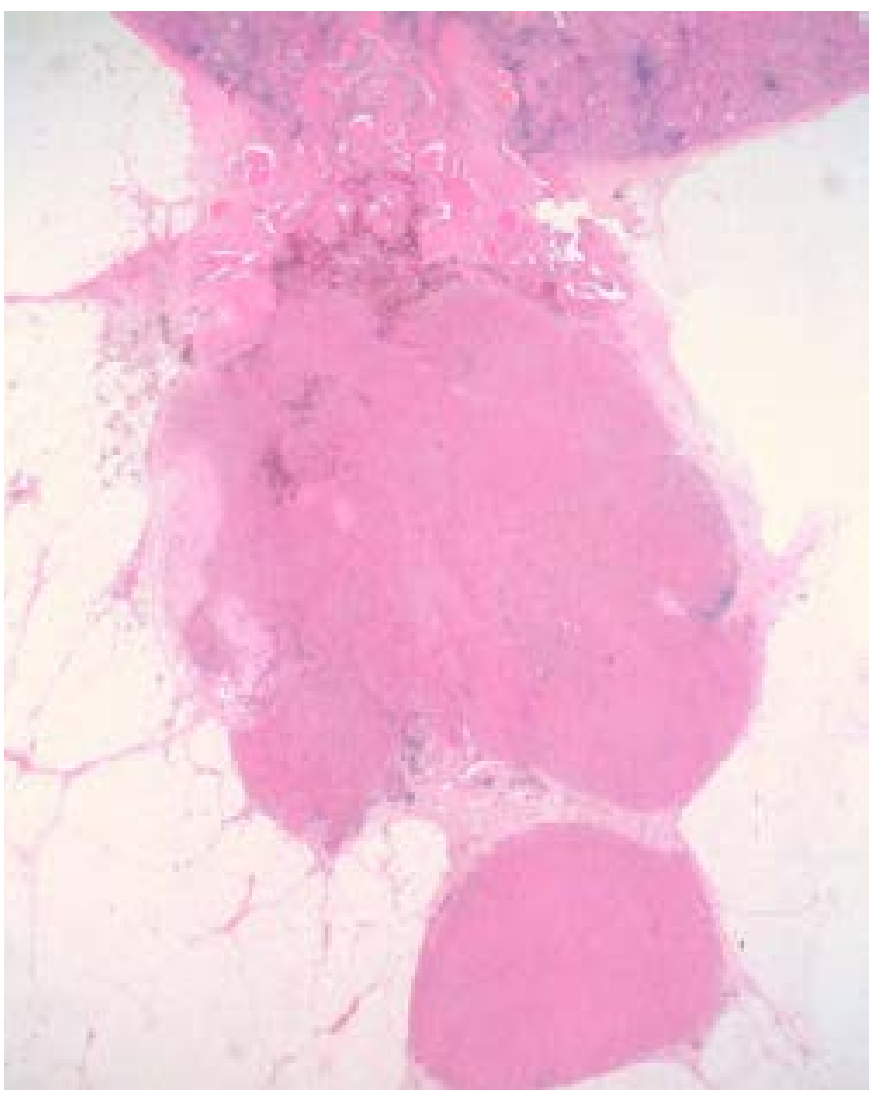

Fig. 3. A low power microscopic view (x4) showing the solid fibro-inflammatory reaction within the perinephric fat related to an adjacent collapsed benign renal cyst.

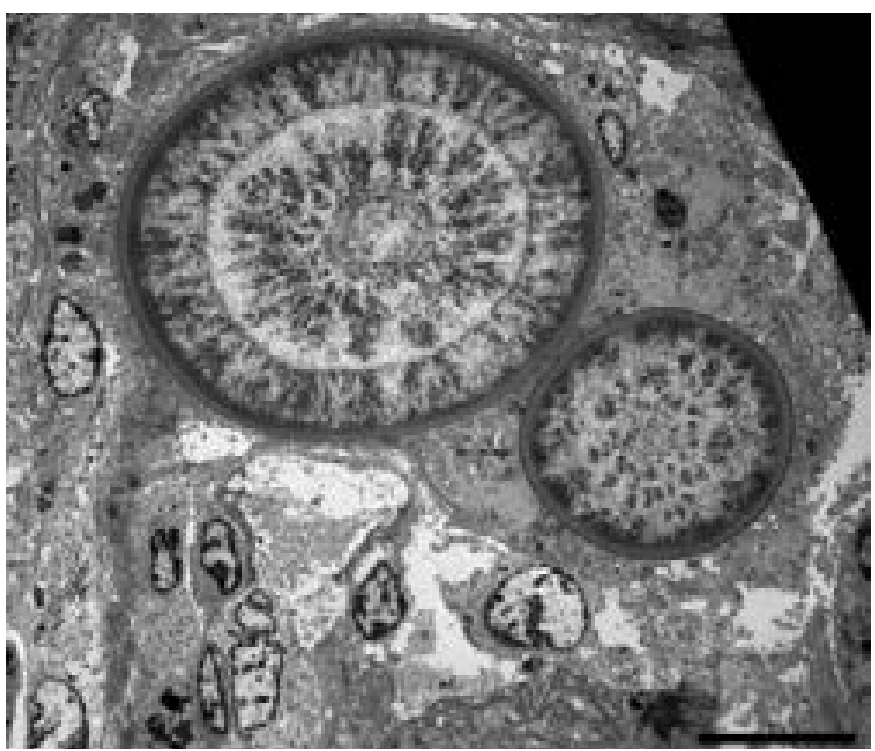

Fig. 5. Electron micrograph of the Liesegang rings showing the concentric lamellar structure, radial cross striations and a central amorphous core (Black bar 10 microns). 
by fibrous tissue and appeared to infiltrate overlying perinephric fat. The background kidney was unremarkable.

Microscopically the lesion consisted of a collapsed, partially ruptured benign cyst which extended into perinephric fat (fig. 3). The cyst was lined by flattened epithelial cells which were strongly positive for pancytokeratin, CK7 and EMA. In addition they were focally positive for CK5/6 and positive for BerEP4, HMBE and vimentin. The epithelial cells were negative for WT1, CEA and calretinin.

Surrounding the cystic lesion were areas of hemorrhage containing hemosiderin laden macrophages and areas of focal fat necrosis. In addition there was evidence of an adjacent pseudotumor formed by an expansile collection of histiocytes and multinucleate giant cells surrounding many concentric non-cellular lamellar structures. These appear to have a peripheral concentric layer with radial cross striations and a central amorphous core. This structural appearance is seen on H\&E, highlighted on PAS (fig. 4) and clearly defined with electron microscopy (fig. 5). The rings stained negative with Von Kossa and Perls' Prussian Blue. The morphology of these structures is characteristic of Liesegang rings.

\section{Discussion}

Liesegang rings are phenomena that are well described in a variety of natural systems including ooitic limestone [1].
These non-cellular laminated structures are the result of a biochemical process involving periodic precipitation from supersaturated solutions. It is thought that nucleating particles decrease the concentration of soluble products in their surroundings, consequently causing a decrease in nucleation rate and precipitation between adjacent regions of sub and super-saturation, resulting in the formation of ring shaped structures $[2,3]$. Liesegang rings have been described in a variety of tissues, cyst aspirates [3] and fluids such as urine [4]. In the kidney they have been very rarely described in hemorrhagic renal cysts, in necrotic tissue adjacent to renal adenocarcinomas, in renal pelvis masses, [5], in xanthogranulomatous pyelonephritis [6] and in a rare renal inflammatory myofibroblastic tumor [7]. In addition they have been mistaken for renal parasites, algae and psammoma bodies [3]. Liesegang rings appear similar to Michaelis-Gutmann bodies and corpora-amylacea but are biochemically distinct [1].

We describe here a ruptured renal cyst with a florid surrounding reaction containing Liesegang rings which mimicked a renal cell carcinoma on radiology resulting in surgical intervention. We are of the opinion that this rare cause of a renal pseudotumor should be kept in mind when considering the differential diagnosis of renal masses.

\section{References}

1 Chikkamuniyappa S, Kadri SM: Liesegang's rings- a morphologic mystery: report of a case and review of the literature. Indian $\mathrm{J}$ Pract Doct 2006;3: No 4

2 Cartwright JH, Garcia-Ruiz JM, Villacampa AI: Pattern formation in crystal growth: Liesegang rings. Comput Phys Commun 1999;121-122:411-413.
-3 Raso DS, Greene WB, Finlay JL, Silverman JF: Morphology and pathogenesis of Liesegang rings in cyst aspirates:Report of two cases with ancillary studies. Diagn Cytopathol 1998;19:116-119.

4 Misselevich I, Zlotnik M, Boss JH: Liesegang rings in hemorrhagic urine. Diagn $\mathrm{Cy}-$ topathol 2004;31:173-174.

$\checkmark 5$ Vizcaino JR, Macedo-Dias JA, Teixeira-de-Sousa JM, Silva RM, Carpenter S: Pseudotumour of renal pelvis: Liesegang rings mimicking a solid neoplasm of the renal pelvis. Histopathology 2005;47:115-117.
6 Pegas KL, Edelweiss MI, Cambruzzi E, Zettler CG: Liesegang rings in xanthogranulomatous pyelonephritis: a case report. Patholog Res Int 2010;2010:602523.

7 Petrescu A, Berdan G, Hulea I, Gaitanidis R, Ambert V, Jinga V, Popescu M, Andrei F, Niculescu L: Renal inflammatory myofibroblastic tumor - a new case report. Rom J Morphol Embryol 2007;48:437-442. 